\title{
PENYULUHAN KESEHATAN TENTANG PENYAKIT KECACINGAN PADA SISWA-SISWI KELAS 3 DAN 4 SD N 01 SUMBER AGUNG KEMILING BANDAR LAMPUNG
}

\author{
https://doi.org/10.33024/jkpm.v4i6.5318
}

\author{
Dimas Ning Pangesti ${ }^{1 *}$, Sarinah Sri Wulan ${ }^{2}$, Indah Kumoro Dewi ${ }^{3}$ \\ ${ }^{1-3}$ Akademi Keperawatan Baitul Hikmah Bandar Lampung \\ Disubmit: 16 Oktober 2021 Diterima: 01 Desember 2021 Diterbitkan: 02 Desember 2021 \\ E-mail : dimasningpangesti@gmail.com
}

\begin{abstract}
ABSTRAK
Kecacingan merupakan salah satu masalah kesehatan masyarakat di Indonesia yang berkaitan erat dengan kondisi lingkungan. Kasus kecacingan di daerah bermacam-macam sesuai dari faktor penyebabnya seperti kelembaban, kondisi tanah, higiene sanitasi, kelompok umur yang diperiksa. Usia anak sekolah salah satu kelompok yang sering terjadi infeksi kecacingan. Kemenkes Ditjen Pengendalian Penyakit dan Penyehatan Lingkungan mengungkapkan bahwa dengan mencuci tangan dapat menurunkan kasus penyakit diare sebanyak $45 \%$. Mencuci tangan dapat menjaga lingkungan serta dapat mengurangi kasus penyakit menular sebanyak $90 \%$ seperti kecacingan. Angka infeksi kecacingan tinggi dipengaruhi oleh kebersihan diri, sanitasi lingkungan dan kebiasaan penduduk yang kurang menjaga kebersihan diri dan lingkungan. Tujuan kegiatan ini siswa dan siswi Kelas 3 dan 4 SD N.01 Sumber agung dapat memahami dan mengaplikasikan perilaku hidup bersih dan sehat dalam kehidupan sehari-hari dengan mengaplikasikan 7 langkah cuci tangan untuk menghindari penyakit kecacingan. Adapun kegiatan yang dilakukan adalah penyuluhan tentang penyakit kecacingan dan simulasi cara mencuci tangan 7 langkah. Alat yang digunakan lefleat dan mobile wastafel. Siswa siswi kelas 3 dan 4 SD N 01 Sumber Agung Kemiling Bandar Lampung dapat menjawab pertanyaan yang disampaikan pemateri dan dapat melakukan 7 langkah cuci tangan.
\end{abstract}

Kata Kunci: Penyakit Kecacingan, kelompok usia sekolah,Cuci tangan 7 langkah,

\begin{abstract}
Worms are one of the public health problems in Indonesia that are closely related to environmental conditions. Cases of worms in the area vary according to the causative factors such as humidity, soil conditions, hygiene and sanitation, and the age group being examined. School age children are one of the groups that often have helminth infections (bisara D, Mardiana, 2010). The Ministry of Health, Directorate General of Disease Control and Environmental Health, revealed that washing hands can reduce cases of diarrheal disease by 45\%. Washing hands can protect the environment and can reduce cases of infectious diseases by $90 \%$ such as worms (Imran Agus N, 2021). The high worm infection rate is influenced by personal hygiene, environmental sanitation and
\end{abstract}


the habits of the population who do not maintain personal and environmental hygiene. The purpose of this activity is that students in Grades 3 and 4 of SD N.01 Sumber Agung can understand and apply clean and healthy living behavior in daily life by applying 7 steps of hand washing to avoid worms. The activities carried out were counseling about helminthiasis and simulations on how to wash hands in 7 steps. The tools used are leaflets and mobile sinks. The 3rd and 4th grade students of SD N 01 Sumber Agung Kemiling Bandar Lampung can answer questions submitted by the speaker and can do 7 steps of washing their hands.

Keywords: Worms Disease, school age group, 7 steps hand washing

\section{PENDAHULUAN}

Kecacingan merupakan salah satu masalah kesehatan masyarakat di Indonesia yang berkaitan erat dengan kondisi lingkungan. Kasus kecacingan di suatu daerah bermacam-macam sesuai dari faktor penyebabnya, antara lain kelembaban, kondisi tanah, higiene sanitasi, Kelompok usia sekolah merupakan kelompok yang sering terkena infeksi kecacingan (Bisara D, Mardiana, 2010)

Cacingan merupakan penyakit menular yang menjadi masalah kesehatan masyarakat di sebagian besar wilayah Indonesia dan dapat mengakibatkan menurunnya kondisi kesehatan, gizi, kecerdasan, dan produktifitas khususnya terhadap pertumbuhan dan perkembangan pada kelompok anak usia sekolah. Upaya pencegahan kasus kecacingan pada masyarakat terutama kelompok anak usia sekolah perlu dilakukan peningkatan pemberdayaan masyarakat dan komitmen lintas program dan lintas sektor melalui penyuluhan dan pendampingan pelaksanaan 7 langkah cuci tangan .

Depkes RI (2005), terdapat jumlah sampel 257 orang dengan hasil penelitian menunjukan perilaku cuci tangan memakai air dan sabun sebelum makan dapat menekan kejadian kecacingan. Pendekatan melalui pendidikan dengan cara penyuluhan dari tim kesahatan atau promosi keshatan melalui sekolah sekolah dasar dengan dasar pencegahan melalui cara cucitangan yang benar.

Data Depkes Provinsi Lampung tahun 2015 prevalensi penyakit kecacingan perut pada anak SD sebesar 60-80\%. Kejadian kecacingan berhubungan dengan perilaku tidak cuci tangan sebelum makan dengan air dan sabun, BAB tidak dijamban, jajan bukan di kantin sekolah dan masih banyak lagi penyebabnya

Didapatkan data awal khusus pada peserta didik Kelas 3A dan 3B sebanyak 48 siswa/i SDN 01 Sumber Agung, Kemiling, Bandar Lampung, tentang kebiasaan mencuci tangan diperoleh hasil prevalensi tidak pernah cuci tangan 23 siswa/I (47\%), jarang cuci tangan 14 siswa/I (30\%), dan selalu cuci tangan 11 siswa/l (23\%).

Berdasarkan latar belakang diatas kami tertarik untuk melakukan Kegiatan pengabdian kepada masyarakat di SD N 01 Sumber Agung Kemiling Bandar lampung kepada siswa/siswi SD kelas 3 dan 4 dengan tema “ 7 langkah cuci tangan untuk mencegah penyakit kecacingan" 


\section{MASALAH}

Berdasarkan wawancara diawal sebelum kegiatan penyuluhan dengan Kepala Sekolah SDN 01 Sumber Agung. Kemiling, Bandar Lampung, didapatkan data selama 1 Semester, peserta didik yang tidak mengikuti proses pembelajaran 65\% dari 322 siswa/i dengan prevalensi penyakit anemia 29 Siswa/l (14 \%), penyakit kecacingan 153 siswa/l (73\%), dan penyakit diare 28 siswa/I (13\%). Dan didapatkan data awal khusus pada peserta didik Kelas 3A \& 3B sebanyak 48 siswa/i SDN 01 Sumber Agung, Kemiling, Bandar Lampung, tentang kebiasaan mencuci tangan diperoleh hasil prevalensi tidak pernah cuci tangan 23 siswa/I (47\%), jarang cuci tangan 14 siswa/I (30\%), dan selalu cuci tangan 11 siswa/l (23\%).
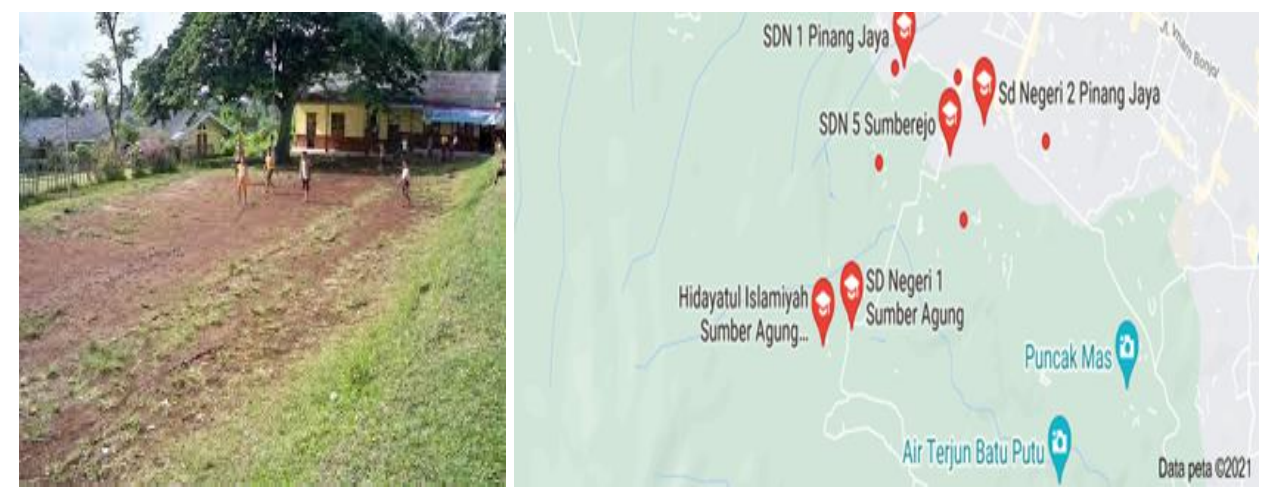

Gambar 2.1 Lokasi Kegiatan Pengabdian di SD N.01 Sumber Agung Kemiling

\section{METODE}

\section{a. Persiapan}

Persiapan dalam kegitan diawali dengan membuat perencanaan dalam bentuk proposal, survey dan meminta surat ijin dengan kepala sekolah, membuat materi penyuluhan dalam bentuk Power Point ( PPT), membuat poster dan lefleat, mempersiapkan alat cuci tangan mobile wastafel, sabun dan tisu pengering untuk demonstrasi cuci tangan 7 langkah

b. Pelaksanaan

Melapor dengan kepala sekolah sekaligus memberikan kata sambutan dan kepala sekolah memberitahukan kepada guru kelas 3 dan 4 untuk mengumpulkan siswa di dalam 1 kelas, untuk mendengarkan penyuluhan dan siswa mengikuti cara 7 langkah cuci tangan dengan benar

c. Evaluasi

1) Struktur

Siswa dan siswi yang hadir ada 78 anak dengan usia berkisar 9 sampai 10 tahun, laki-laki dan perempuan, asal dari desa Sumber Agung Kemiling Bandar Lampung. Tempat sudah sesuai yang disiapkan di ruang kelas 4 yang dilengkapi dengan meja dan kursi, LCD, leptop, pointer, pengeras suara. Materi selesai disampaikan, siswa dan siswi memahami dan sangat antusias, proses kegiatan berjalann dengan lancar.

2) Proses

Pelaksanaan dilakukan Kamis, 16 November 2016, jam 09.00 sampai dengan $12.00 \mathrm{WIB}$ 


\section{HASIL DAN PEMBAHASAN}

Pelaksanaan dalam kegiatan penyuluhan dan dan demonstrasi pelaksanaan cuci tangan bersama siswa kelas 3 dan 4 SD N.01 Sumber Agung kemiling dilakukan pada hari Kamis, 16 November 2016. Pelaksanaan PKM di tujukan kepada siswa dan siswi kelas 3 dan 4, di awali dengan penyuluhan tentang penyakit kecacingan dan langkah- langkah cuci tangan.

Penyampaian materi kurang lebih 90 menit, dan dilanjutkan dengan tanya jawab dan demontrasi 7 langkah cuci tangan kurang lebih 60 menit, siswa siswi sangat antusias dalam kegiatan ini, mahasiswa ikut serta membantu memotifasi dan memfasilitasi siswa siswi dalam menyampaikan pertanyan dan cara cuci tangan dengan 7 langkah.

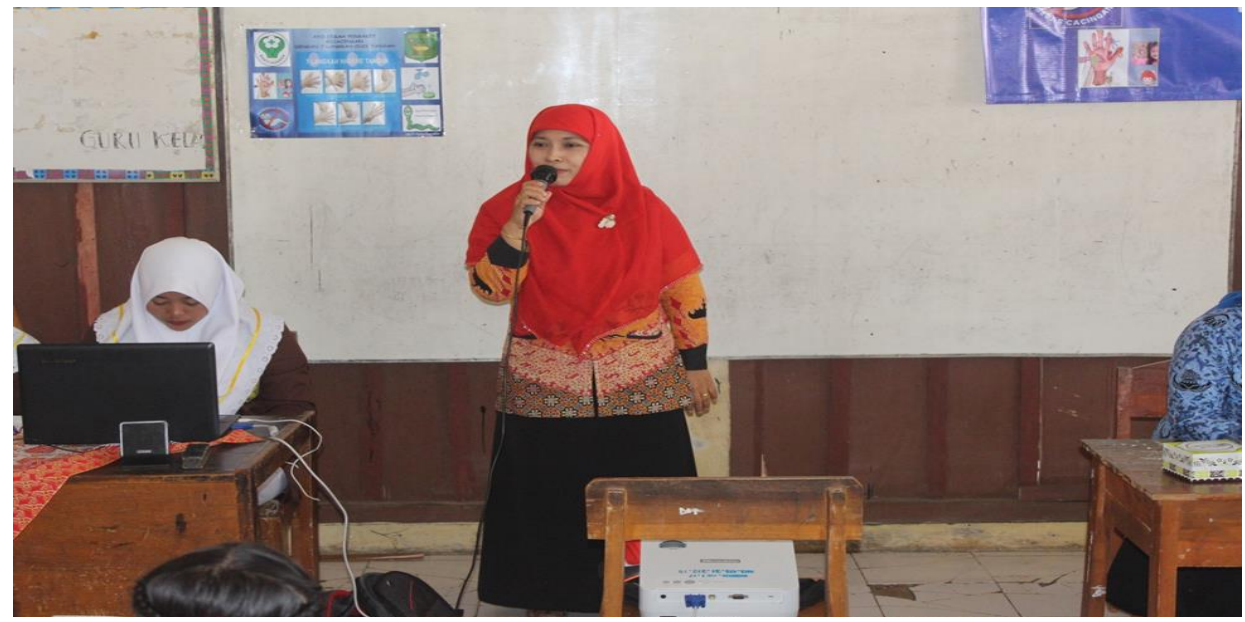

Gambar 4.1. Foto penyampaian materi penyuluhan Kesehatan

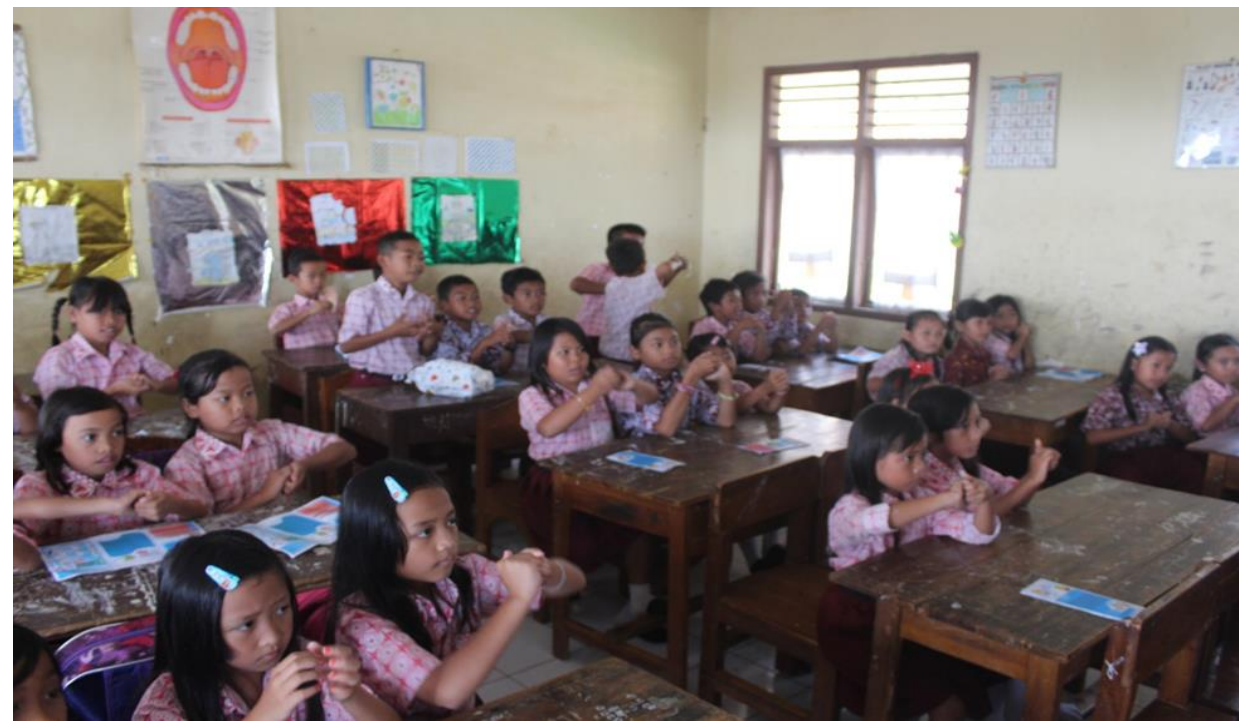

Gambar 4.2. Foto Redemonstrasi cuci tangan 7 langkah 


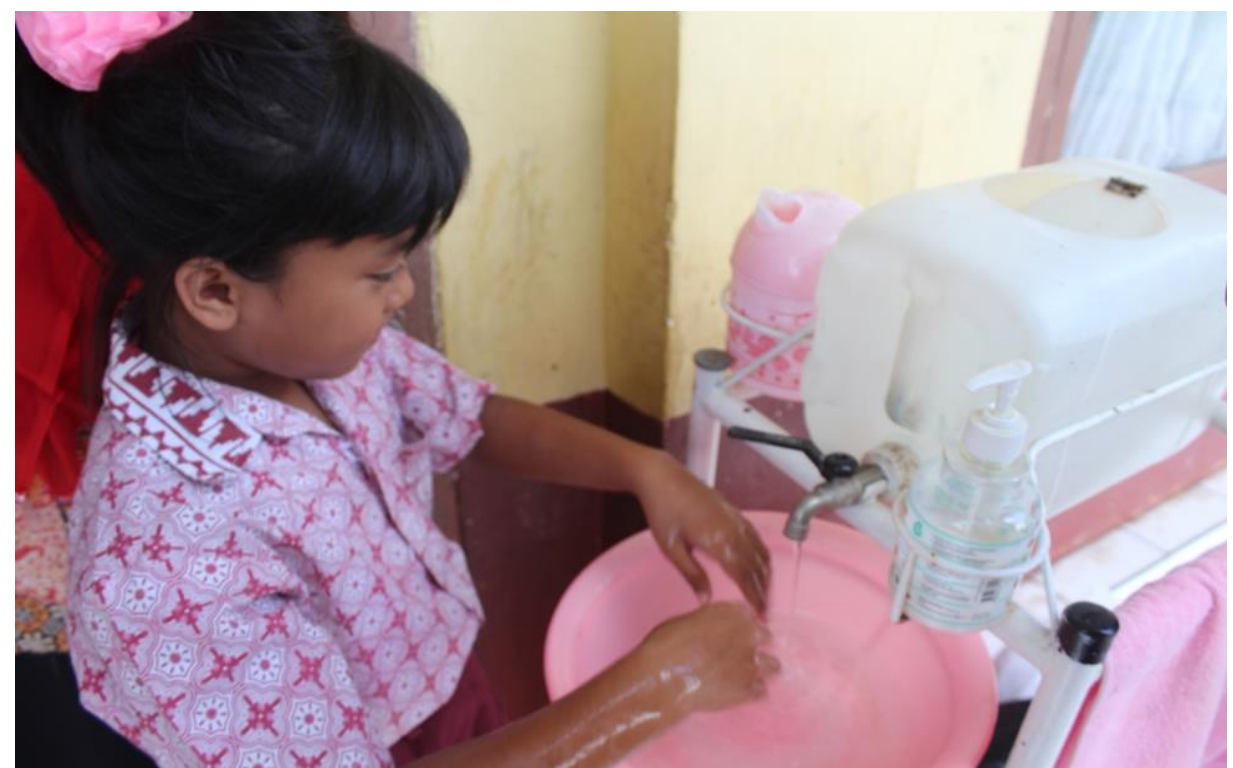

Gambar 4.1. Foto praktik cuci tangan 7 langkah

\section{KESIMPULAN}

Penyuluhan kesehatan dan demonstrasi 7 langkah cuci tangan yang diberikan pada kelompok masyarakat khususnya siswa-siswi kelas 3 dan 4 SD N 01 Sumber Agung Kemiling Bandar Lampung, dalam pelaksanaannya Materi penyuluhan yang disampaikan mencakup pengertian penyakit kecacingan, penyebab, tanda gejala, pemeriksaan penunjang, komplikasi, faktor resiko, pencegahan penularan penyakit kecacingan dan 7 langkah cuci tangan. Materi tersebut dapat disampaikan dan dapat diterima serta dimengerti dan dipahami dengan baik oleh siswa dan siswi.

6. DAFTAR PUSTAKA

Asiedu, M. S. (2011). Hand washing practices among school children in Ghana.

Bisara, D. Mardiana. (2010). Kasus kecacingan pada murid sekolah dasar dikecamatan Mentewe, Kabupaten Tanah Bumbu KalimantanSelatan https://media.neliti.com/media/publications/82621-ID-kasuskecacingan-pada-murid-sekolah-dasa.pdf di akses 12 November 2016

Departemen Kesehatan. (2006). Keputusan menteri kesehatan No 424/menkes/sk/VI/2006 tentang Pedoman pengendalian cacingan.

Fazlin, S.d kk. (2013). Tingkat pengetahuan siswa tentang mencuci tangan yang benar terhadap kejadian diare di SD 01 Pontianak Utara. https://core.ac.uk/download/pdf/324201991.pdf diakses 10 September 2016

Irman, D. dkk. (2013). Higienitas kuku tangan dan infestasi ascaris lumbricoides dan Trichuuris trichuira pada murud SD negri 40 Meranti Pandak Kecamatan Rumbai Pesisir Pekanbaru, Artikel Penlitian,[Online] http:// repository.unri.ac.id diakses 13 November 2016. 
Judarwanto, W. (2008). Perilaku makan anak sekolah (http://gizi.depkes.go.id/wp-content/uploads/2012/05/perilakumakan-anaksekolah.pdf) diakses pada 25 November 2016

Mustakim. (2013). Hubungan sanitasi lingkungan dan perilaku anak terhadap infeksi penyakit cacingan pada anak di SDN 028 Kelurahan Madani kacamata Reteh Indragiri Hilir tahun 2013, Skripsi. StiKes Hang Tuah, Pekanbaru.

Notoatmodjo, S. (2003). Ilmu kesehatan masyarakat prinsip-prinsip dasar, PT Rineka Cipta, Jakarta.

Notoatmodjo S. (2010). Promosi kesehatan teori dan aplikasi, PT Rineka Cipta, Jakarta

PerMenKes. RI. (2017). "Penanggulangan cacingan" http://hukor.kemkes.go.id/uploads/produk_hukum/PMK_No._15_t tg_Penanggulangan_Cacingan_.pdf diakses 17 Oktober 2016

WHO. (2012). " 7 langkah cara cuci tangan yang benar menurut WHO. http://dinkes.sumutprov.go.id/artikel/7-langkah-cara-mencucitangan-yang-benar-menurut-who 